\title{
Seasonal residency, habitat use, and site fidelity of juvenile sand tiger sharks Carcharias taurus in a Massachusetts estuary
}

\author{
Jeff Kneebone $^{1, *}$, John Chisholm ${ }^{2}$, Gregory B. Skomal ${ }^{2}$ \\ ${ }^{1}$ University of Massachusetts Dartmouth, School for Marine Science and Technology, 200 Mill Road, Suite 325, \\ Fairhaven, Massachusetts 02719, USA \\ ${ }^{2}$ Massachusetts Marine Fisheries, 838 South Rodney French Boulevard, New Bedford, Massachusetts 02744, USA
}

\begin{abstract}
The sand tiger shark Carcharias taurus is a large coastal species that has endured marked declines in its western North Atlantic population over the past $30 \mathrm{yr}$. In the face of these declines, identification of nursery areas for this species is of particular importance to ensure the implementation of protective measures that will maximize survival of young individuals to maturity. Passive acoustic telemetry was used to assess the emergence of Plymouth, Kingston, Duxbury (PKD) Bay, Massachusetts, USA, as a seasonal nursery for juvenile sand tigers that migrate north from southern parturition grounds. Seasonal residency, habitat use, and site fidelity of 73 acoustically tagged juvenile sand tigers (78 to $108 \mathrm{~cm}$ fork length) were monitored within PKD Bay during 4 seasonal periods from 2008 to 2011. Eight individuals were tracked in multiple years, with 2 individuals returning to PKD Bay in 3 consecutive years. Sand tigers remained in PKD Bay for periods of 1 to $124 \mathrm{~d}$ and displayed a high degree of site fidelity to 2 core habitats during each year of the study. Weekly activity space estimates were relatively constant throughout each yearly monitoring period, with a general increase prior to emigration of sharks from the embayment. Emigration of sharks from PKD Bay was significantly related to both day length and water temperature. Collectively, these results suggest that PKD Bay constitutes a seasonal nursery area for juvenile sand tigers and warrants the extension of juvenile sand tiger essential fish habitat north of Cape Cod, Massachusetts, USA.
\end{abstract}

KEY WORDS: Sand tiger $\cdot$ Acoustic telemetry $\cdot$ Site fidelity $\cdot$ Residency $\cdot$ Habitat use $\cdot$ Nursery

\section{INTRODUCTION}

The importance of coastal nursery habitats to the productivity of shark populations has been widely acknowledged by researchers and fisheries management agencies (NMFS 1999, Merson \& Pratt 2001, NMFS 2006, Heithaus 2007, Heupel et al. 2007, McCandless et al. 2007). These habitats, commonly believed to foster the growth of juveniles to maturity through various mechanisms (reviewed by Heithaus 2007), are considered essential fish habitat (EFH) in the United States under the Sustainable Fisheries Act (1996) 1 and therefore are mandated to be identified and described throughout a species' geographic range. Recently, the importance of properly identifying these habitats has also increased in light of documented declines in shark populations (e.g. sandbar shark; NMFS 2006) and evidence of the importance of juvenile survival to shark population growth and, hence, recovery rates (e.g. Cortés 2002, Goldman 2002, Beerkircher et al. 2003, Carlson et al. 2003, Aires-da-Silva \& Gallucci 2007). Given the potential benefits of nursery areas to the maintenance of popu-

\footnotetext{
1Magnuson-Stevens Fishery Conservation and Management Act. 1996. Public Law 94-265, amended 11 October 1996
} 
lations, a thorough spatial and temporal understanding of how shark populations use nursery habitats should improve conservation and management efforts (NMFS 2006, Heupel et al. 2007), particularly for highly exploited species (Conrath \& Musick 2010).

The sand tiger Carcharias taurus is a large coastal shark that ranges from the Gulf of Mexico to the Gulf of Maine in the western North Atlantic Ocean (WNA; Bigelow \& Schroeder 1953). Historically, the species has been fished directly and/or taken as bycatch throughout this range, and there is some evidence of population declines as high as 80 to $90 \%$ since the mid-1970s (Musick et al. 1993, Castro et al. 1999, Musick et al. 2000). In 1997, as a precautionary measure and to curtail fishing mortality, the National Marine Fisheries Service (NMFS) prohibited the possession of this species in United States federal waters (NMFS 1999) and, in 2004, designated the sand tiger a Species of Concern. More recently, the Atlantic States Marine Fisheries Commission (ASMFC) mandated the same prohibition of sand tiger retention in all state waters along the Atlantic coast of the United States from Florida to Maine (ASMFC 2008).

Although these protective measures are likely beneficial to the sand tiger population in the WNA, their effectiveness remains largely unknown because of a persistent lack of critical biological, ecological, and fisheries data on this species. For example, Carlson et al. (2009) were unable to provide a definitive update on the population status of sand tigers in the WNA, despite the inclusion of updated life history information (e.g. Goldman et al. 2006) and catch data. The lack of a viable population assessment for this species is particularly problematic given the results of the demographic analysis conducted by Goldman (2002), which suggested that the sand tiger population in the WNA may be more sensitive to fishing mortality than previously thought and may still be decreasing slightly. Collectively, these findings highlight the need for a better general understanding of the sand tiger population in the WNA, particularly for factors that will contribute to the growth and recovery of the population.

Sand tiger nursery habitat is only broadly defined along the east coast of the United States (Compagno 2001). Although no specific pupping areas have been identified, parturition is thought to occur from December to March off Florida (Gilmore et al. 1983, Gilmore 1993), in February and March off North Carolina/Virginia (Branstetter \& Musick 1994, Goldman et al. 2006), or throughout its WNA range from March to April (Compagno 2001). After parturition, neonate and juvenile sand tiger sharks are thought to migrate north to summer nursery habitats from North Carolina to Cape Cod, returning to southern latitudes during winter months (Bigelow \& Schroeder 1953, Gilmore et al. 1983, Gilmore 1993). Although specific nursery areas have been identified in several estuaries (Chesapeake, Delaware, Sandy Hook, and Narragansett bays) and coastal sounds (NMFS 2009), fine-scale spatial and temporal data on seasonal residency, localized abundance, and habitat use are lacking for these areas.

Based on Springer's (1967) criteria for qualifying shark nursery habitat, Skomal (2007) identified the coastal waters of Massachusetts as secondary nursery habitat for neonatal and juvenile sand tigers that move north from southern pupping grounds (Gilmore et al. 1983, Gilmore 1993). However, this assertion was based on opportunistic sampling of 10 individuals over a 13 yr period and therefore was not a robust assessment of the occurrence of nursery habitat in this area. In recent years, an increasing number of juvenile sand tigers have been incidentally taken by commercial and recreational fishermen in Plymouth, Kingston, Duxbury (PKD) Bay, a tidal estuary located on the Massachusetts coast in the Gulf of Maine (J. Chisholm \& G. B. Skomal unpubl. data). Anecdotal evidence indicates that the strong seasonal presence (late spring to early fall) of sand tigers in PKD Bay is a relatively new phenomenon; local fishermen claim that they have not seen this species in large numbers until recently (J. Chisholm unpubl. obs., J. Hilliard \& D. Lindamood pers. comm.). These observations of increased abundance are particularly important because this area represents the northern limit of the species' seasonal distribution, where sand tigers were rarely encountered historically (Bigelow \& Schroeder 1953). Moreover, no nursery habitat (i.e. EFH) has been documented or described for this species north of Cape Cod (NMFS 2009). The objectives of the present study were to employ passive acoustic telemetry to document and quantify seasonal residency, habitat use, and site fidelity of sand tigers within PKD Bay, and to determine the extent to which this embayment serves as an important seasonal nursery area in a region where this species is not well understood.

\section{MATERIALS AND METHODS}

\section{Study site}

PKD Bay is a coastal embayment located along the south shore of Massachusetts about $50 \mathrm{~km}$ southeast of Boston (Fig. 1). The bay is characterized by several 

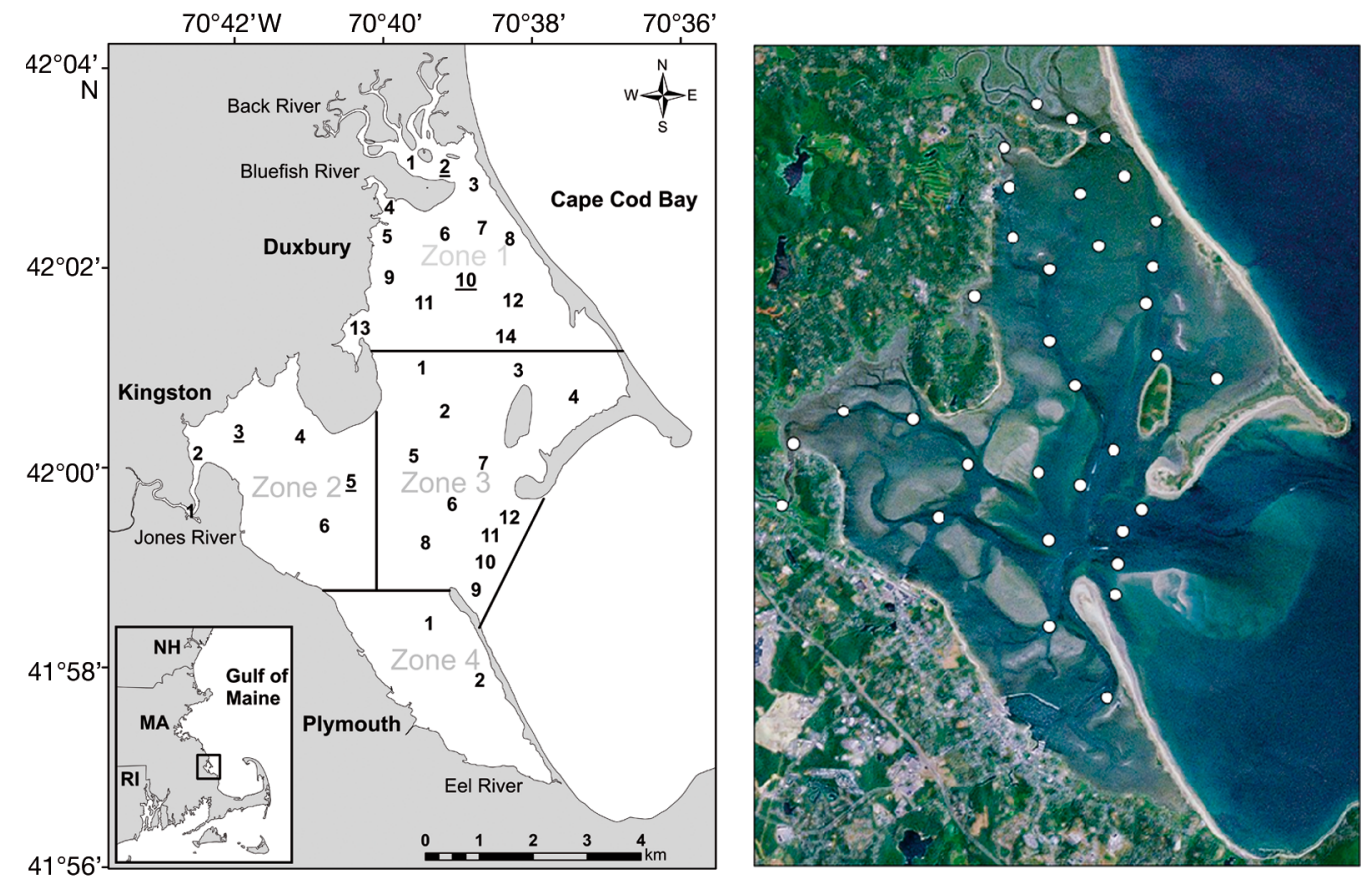

Fig. 1. Plymouth, Kingston, Duxbury (PKD) Bay, Massachusetts, USA, including location of all receivers deployed over the course of the study. Zone boundaries (solid lines) and receiver locations (left-hand panel, numbers; right-hand panel, white circles) are presented. Refer to Table 1 for details on the deployment of specific receivers in each monitoring period. Temperature data used in all statistical analyses were obtained from underlined receiver numbers (left-hand panel)

large channels surrounded by sand/mud flats, salt marshes, and tidal creeks, which are exposed at low tide. Four freshwater streams enter PKD Bay: Back River, Bluefish River, Jones River, and Eel River. PKD Bay is bounded on its eastern side by 2 barrier beaches separated by a $2 \mathrm{~km}$ opening to Cape Cod Bay. Tidal exchange is semidiurnal, with a mean tidal amplitude of $3.2 \mathrm{~m}$. On average, the total surface area of the bay fluctuates between 22.1 and $40.7 \mathrm{~km}^{2}$ at mean low and mean high water, respectively, resulting in a $66.1 \%$ tidal exchange in water volume (Iwanowicz et al. 1974). Average overall depth increases from 2.1 to $3.3 \mathrm{~m}$ from mean low and mean high water, respectively. Bottom substrates include mud, sand, and eelgrass Zostera marina, with a considerable area $\left(0.312 \mathrm{~km}^{2}\right)$ of substrate occupied by shellfish propagation grants, primarily in the northern portion of the bay (R. Kesler pers. comm.).

\section{Shark capture and tagging}

Using conventional rod and reel tackle, circle hooks (size 8/0), and chunks of menhaden Brevoortia tyrannus for bait, juvenile sand tigers were captured in various regions of PKD Bay from a small $(6.1 \mathrm{~m})$ center console research vessel during the periods of
August to September 2008 and June to October 2009 to 2011. All sharks were captured, handled, and released in accordance with Massachusetts Division of Marine Fisheries regulations. Once landed, each shark was removed from the water, the hook was removed (if possible), and tonic immobility was induced by restraining the shark ventral side up in a V-shaped table lined with pre-wetted neoprene (Watsky \& Gruber 1990). All sharks captured throughout the study period were tagged externally with conventional NMFS shark tags (Kohler \& Turner 2001), and a subset was tagged internally with individually coded acoustic transmitters (2008 and 2009: model V16-4L [nominal delay $=30$ to $90 \mathrm{~s}$, life = 2779 d]; 2010: models V16-4L and V16T-4L [nominal delay $=45$ to $135 \mathrm{~s}$, life $=3650 \mathrm{~d}$ ]; $2011:$ models V16T$4 \mathrm{~L}$ [nominal delay $=45$ to $135 \mathrm{~s}$, life $=3280 \mathrm{~d}$ ], V9AP$2 \mathrm{~L}$ [nominal delay $=60$ to $180 \mathrm{~s}$, life $=123 \mathrm{~d}$ ], and V9AP-2H [nominal delay $=60$ to $180 \mathrm{~s}$, life $=81 \mathrm{~d}$ ]; Vemco Division, AMIRIX Systems). Tags were implanted in the body cavity through a small (2 to $3 \mathrm{~cm}$ ) abdominal incision on the ventral side of the shark along the midline, anterior to the pelvic fins. The incision was closed with 3 to 4 interrupted sutures (2-0 PDS II, Ethicon). Prior to release, fork length ( $\mathrm{FL}_{\mathrm{i}} \mathrm{cm}$ ) and sex were recorded. All surgical procedures were completed within 5 to $10 \mathrm{~min}$, and sharks were held 
in the water at the side of the vessel to recover immediately following surgery.

Preliminary capture and tagging data collected during 2008 and early 2009 suggested that sand tigers were distributed in 2 separate regions of PKD Bay and exhibited strong fidelity to each region. As a result, efforts were made to distribute tagging effort equally between these 2 regions to generate a more robust understanding of shark behavior in PKD Bay.

Table 1. Summary of detections per day and detections per total receiver days (Detections/Rday) data for all receivers deployed in each zone (Z1 to Z4) during each seasonal monitoring period (2008 omitted). Blank values indicate that a receiver was not deployed at that location during the corresponding monitoring period

\begin{tabular}{|c|c|c|c|}
\hline Receiver & 2009 & 2010 & 2011 \\
\hline Z1-1 & 143 & 143 & 71 \\
\hline $\mathrm{Z} 1-2$ & $1000^{\mathrm{a}}$ & $716^{\mathrm{a}}$ & $441^{\mathrm{a}}$ \\
\hline $\mathrm{Z1}-3$ & 598 & 692 & 382 \\
\hline Z1-4 & 44 & 35 & 3 \\
\hline $\mathrm{Z} 1-5$ & & $\mathrm{~b}$ & $10^{\mathrm{a}}$ \\
\hline Z1-6 & & $\mathrm{b}$ & 89 \\
\hline $\mathrm{Z} 1-7$ & & & $184^{\mathrm{a}}$ \\
\hline $\mathrm{Z1-8}$ & & & 77 \\
\hline Z1-9 & & & 3 \\
\hline $\mathrm{Z} 1-10$ & $181^{\mathrm{a}}$ & $221^{\mathrm{a}}$ & $85^{\mathrm{a}}$ \\
\hline Z1-11 & 165 & & 26 \\
\hline Z1-12 & 26 & 53 & 20 \\
\hline Z1-13 & 67 & 100 & $9^{\mathrm{a}}$ \\
\hline Z1-14 & & & 6 \\
\hline Detections/Rday & 323 & 294 & 103 \\
\hline $\mathrm{Z} 2-1$ & 2 & 6 & 2 \\
\hline $\mathrm{Z} 2-2$ & & 316 & 182 \\
\hline $\mathrm{Z} 2-3$ & $\mathrm{~b}$ & $271^{\mathrm{a}}$ & $211^{\mathrm{a}}$ \\
\hline $\mathrm{Z} 2-4$ & 39 & 294 & 311 \\
\hline $\mathrm{Z} 2-5$ & $97^{\mathrm{a}}$ & $91^{\mathrm{a}}$ & $39^{\mathrm{a}}$ \\
\hline $\mathrm{Z} 2-6$ & 14 & 19 & 7 \\
\hline Detections/Rday & 39 & 165 & 129 \\
\hline Z3-1 & 53 & $117^{\mathrm{a}}$ & $7^{a}$ \\
\hline Z3-2 & & & 3 \\
\hline Z3-3 & $10^{\mathrm{a}}$ & $16^{\mathrm{a}}$ & $5^{\mathrm{a}}$ \\
\hline $\mathrm{Z} 3-4$ & & & $3^{a}$ \\
\hline Z3-5 & 10 & 6 & 1 \\
\hline Z3-6 & & & $2^{\mathrm{a}}$ \\
\hline $\mathrm{Z} 3-7$ & 5 & 6 & 1 \\
\hline Z3-8 & 44 & 9 & 1 \\
\hline Z3-9 & & 9 & 1 \\
\hline Z3-10 & 4 & $9^{\mathrm{a}}$ & $0.4^{\mathrm{a}}$ \\
\hline Z3-11 & 3 & 7 & 0.3 \\
\hline Z3-12 & 2 & 1 & $\mathrm{~b}$ \\
\hline Detections/Rday & 10 & 20 & 2 \\
\hline Z4-1 & & 11 & 2 \\
\hline $\mathrm{Z} 4-2$ & $5^{\mathrm{a}}$ & $13^{\mathrm{a}}$ & $4^{\mathrm{a}}$ \\
\hline Detections/Rday & 5 & 12 & 3 \\
\hline
\end{tabular}

\section{Receiver deployment and acoustic monitoring}

To assess fine-scale movement patterns and habitat use of juvenile sand tigers within PKD Bay, a fixed acoustic receiver array (model VR2W, Vemco Division, AMIRIX Systems) was deployed annually during 4 seasonal monitoring periods from 2008 to 2011. The total number and locations of receivers varied considerably between and during all monitoring periods because of the acquisition of new receivers and the loss of existing receivers (Fig. 1, Table 1). In short, 15 receivers were deployed from August to October 2008, 21 were deployed from June to October 2009, 24 were deployed from May to October 2010, and 34 were deployed from May to October 2011. Receivers were downloaded and cleaned monthly during each deployment period. Prior to analysis, all transmitter data were examined individually, and false detections were rejected using criteria established by Vemco (Pincock 2012).

To examine the potential effects of temperature on juvenile sand tiger distribution within PKD Bay, several temperature loggers (model HOBO Pendant, Onset Computer Corporation) were deployed in each monitoring season (2009: $\mathrm{n}=5$; 2010: $\mathrm{n}=8$; 2011: $\mathrm{n}=13$; Table 1). All loggers were set to record temperature $\left({ }^{\circ} \mathrm{C}\right.$ ) every $30 \mathrm{~min}$ (on the half hour and hour) with an accuracy of $\pm 0.7^{\circ} \mathrm{C}$ (range $=20$ to $70^{\circ} \mathrm{C}$ ). Loggers were deployed on specific receivers during each monitoring period, and only temperature data from loggers deployed in identical locations during each sampling season were used in statistical analyses.

Acoustic range tests were performed on a subset of receivers deployed in various depths and substrates (e.g. tidal flats and channels) both during and after the shark's residency in PKD Bay. During each test, a stationary control tag was deployed sequentially at $50,100,200,300,400$, and $500 \mathrm{~m}$ from the receiver in all 4 cardinal directions, and the number of detections were monitored for $5 \mathrm{~min}$. On average, the detection radius of receivers ranged from $\sim 100 \mathrm{~m}$ in water depths $<3 \mathrm{~m}$ to $\sim 350 \mathrm{~m}$ in water depths $>5 \mathrm{~m}$. In addition, the detection range of receivers positioned in 'deep' (>3 m at low tide) channels was not symmetrical in all cardinal directions, being much greater along the axis of the channel and reduced in shallower water along each side of the channel. Although the overall detection range for some receivers was reduced during low tide, the restriction of sharks to deeper channels during these periods (much of the submerged area goes dry at low tide), where detection range remained high, permitted the detection of 
tagged sharks throughout the entire tidal cycle; data correction to account for receiver range was therefore unnecessary.

\section{Residency}

Seasonal residency of sand tiger sharks within PKD Bay was assessed by tabulating the total number of days that each shark remained within the embayment during each seasonal monitoring period. A day of residency was defined as any day that a tagged shark was detected at least 2 consecutive times on one or more receivers in the array. Given that any movement in or out of PKD Bay must occur through the single opening to Cape Cod Bay to the east, a series of receivers positioned in this region permitted the identification of any sharks that left the embayment (Fig. 1). As a result, all sharks were considered residents of PKD Bay from the time of tagging (or reentrance) until their departure through the mouth of the bay. Departure was confirmed if sharks were detected on receivers at the mouth of the bay and not on any 'interior' receiver in successive days.

Since the amount of time a given shark spent in PKD Bay prior to its capture/tagging was unknown, calculation of its true residence time (TRT) during the tagging year was not possible. As a proxy, minimum residence time (MRT) was calculated as the number of days that a shark remained within the embayment during the year it was tagged. However, TRT for tagged sharks that returned to the embayment in successive years could be calculated as the number of days between their arrival and departure from PKD Bay. The effect of shark length, sex, and year on residence time was examined by linear regression in the R statistical environment (R Core Development Team 2011). Statistical significance was accepted at $p=0.05$. Low sample sizes precluded evaluation of the effects of year, sex, or shark length solely on TRT; thus, data were pooled from all sharks with MRT of at least $42 d$, the shortest observed TRT $(n=60)$. The number and percentage of sharks that exited PKD Bay in each month (July to October) was also calculated as the number of sharks that exited in a month divided by the total number of sharks that exited (i.e. minus deceased individuals).

Detection data were analyzed in conjunction with photoperiod (day length) and water temperature data to examine potential environmental cues for emigration of juvenile sand tigers out of PKD Bay. Generalized linear mixed models (GLMMs), assuming a binomial distribution and a logit link function, were constructed to examine the effects of average weekly day length $(\mathrm{h})$ and water temperature $\left({ }^{\circ} \mathrm{C}\right)$ on the presence of sand tigers in PKD Bay (Zuur et al. 2009). In each year, individual sand tigers were coded as present (1) or absent (0) during each of the $13 \mathrm{wk}$ spanning August 3 to October 31. Sharks were coded as present only if present for at least $3 \mathrm{~d}$ of a given week. Day length data were obtained using times of sunrise and sunset. Average weekly temperatures were calculated as the mean weekly temperature measured by the 4 temperature loggers deployed in areas of highest sand tiger activity (Fig. 1). Since detections from each individual shark over time are not independent, 'shark' was incorporated into the model as a random effect to quantify variation of the fixed effects parameters across individuals. In addition, day length and temperature data were highly correlated (Pearson correlation coefficients: 0.77 to 0.82 ); therefore, separate GLMMs were run for each parameter. Analyses were conducted across years to examine interannual variation in potential migratory cues. Parameter estimates were obtained using Laplace approximation in the 'lme4' package in R (Bates et al. 2011). Zuur et al. (2009) cautioned against assessing statistical significance at p-values close to the 0.05 level in GLMMs and generalized additive mixed models (GAMMs), instead suggesting that 'safe' statistical inference can be made based on p-values of 0.001 or less. Accordingly, significant relationships from mixed models were accepted at $p<0.001$. The residual deviance of each model, steepness of the resulting logistic curve, and similarity of the estimated value at the inflection point between years were used to evaluate the influence of each potential cue.

\section{Habitat use and site fidelity}

To assess areas of high use, the total number of detections of tagged sand tigers was tabulated for each receiver deployed during each monitoring period. Since not all receivers were deployed for an equal length of time and, therefore, did not have an equal probability of detecting tagged sharks, data standardization was necessary to compare the number of detections logged by each receiver. For each receiver, the number of detections per day was calculated as the total number of detections accrued over an entire monitoring period divided by the number of days a receiver was deployed during which at least 1 tagged sand tiger was detected on any 2 receivers in the full array. Receivers were then grouped into 4 zones (Zones 1 to 4 ) based on our preliminary obser- 
vations of shark distribution (Fig. 1). The spatial distribution of sharks in each zone was compared by dividing the total number of detections in each zone by the cumulative number of days that the receivers were deployed in that zone (to account for inconsistencies in the number of receivers deployed in each zone). Detection data were not statistically compared between or within years because of differences in transmitter specifications and inconsistencies in the number and distribution of receivers deployed between zones and monitoring periods. For general comparisons between and within years, receivers were coded based on the full array in $2011(n=34)$ and examined for relative trends.

The center of activity (COA) of each tagged sand tiger within PKD Bay was calculated every hour using the mean position algorithm originally described in Simpfendorfer et al. (2002). Briefly, the COA position represents the average geographic position of an individual within the $1 \mathrm{~h}$ period and provides a more realistic depiction of the habitat used by an individual than raw receiver locations. All COA positions were used to calculate the activity space of tagged sharks within PKD Bay.

Given the irregular boundaries, the presence of islands and salt marsh, and the deployment pattern of the acoustic receivers in PKD Bay, conventional estimators of animal home range and activity space, such as minimum convex polygons and kernel analyses, were not suitable for the robust estimation of these ecological parameters. Instead, a lattice-based density estimator (Barry \& McIntyre 2011) was used to generate estimates of activity space for all tagged fish. Activity spaces (50 and 95\%) were calculated seasonally (total activity space) and weekly (20 wk; June 1 to October 18) for all tagged sharks monitored during each year to assess 'core' areas of sand tiger activity and changes over time. Only sharks monitored for at least $3 \mathrm{~d}$ in a given week were included in the analysis. Empirical estimation of the optimal smoothing parameter $(\mathrm{k})$ using unbiased cross-validation was problematic because of the dispersion of COA positions (i.e. many positions in the same location and/or nearby). Instead, a fixed $\mathrm{k}$ value, obtained by visual inspection of resulting density estimates generated by varying $\mathrm{k}$ values, was used for all analyses. Direct statistical comparison of activity space between years was not appropriate because of interannual differences in the receiver array; however, data were inspected visually between each monitoring period to assess trends. All lattice-based estimates of activity space were obtained using the 'latticeDensity' package in R (Barry 2011).
To investigate the effects of shark sex and size (FL) on total activity space, generalized linear models assuming a Gaussian distribution were applied to log-transformed total activity space estimates. Since weekly activity space estimates consisted of repeated measurements for an individual, the effect of sex, size, week, and average weekly water temperature on activity space was assessed using GAMMs (Zuur et al. 2009) in the 'gamm4' package in R (Wood 2011), with 'shark' incorporated as a random effect. Exploratory data analysis indicated a high degree of correlation between week and average weekly water temperature; therefore, separate regressions were run to examine the individual effects of these factors on weekly activity space. Analyses were run separately for each year of the study. Data from the brief 2008 monitoring period were not included in any of these analyses.

Site fidelity to each zone was assessed through a residency index (March et al. 2010) calculated by dividing the total number of days an individual was detected on any receiver within a zone by the total number of days an individual was detected in the array as a whole. Site fidelity index (SFI) values ranged from 0 (no residency) to 1 (high residency) with SFI $=0.5$ set as the lower limit for 'strong' site fidelity. Only sharks tracked more than $10 \mathrm{~d}$ were included in the analysis; site fidelity was calculated for each year a shark returned to PKD Bay. A BrayCurtis similarity matrix of SFI values was computed between individual sharks, and non-metric multidimensional scaling (nMDS) ordinations were performed using the 'vegan' package in R (Oksanen et al. 2011) to graphically depict differences in site fidelity/habitat use of individual sharks within the study area.

\section{RESULTS}

A total of 111 juvenile sand tigers (62 male and 49 female), ranging in size from 78.0 to $120.0 \mathrm{~cm}$ FL $(91.5 \pm 8 \mathrm{~cm}$; overall mean $\pm \mathrm{SD})$, were captured within Zones 1 and 2 of PKD Bay during 4 summer sampling seasons spanning 2008 to 2011 (Table S1 in the Supplement at http://www.int-res.com/articles/ suppl/m471p165_supp.pdf). Of these, 73 (39 male, 34 female; 78.0 to $108.0 \mathrm{~cm} \mathrm{FL;} 90.6 \pm 7.4 \mathrm{~cm}$ ) were surgically implanted with acoustic transmitters. Eight of these fish returned to PKD Bay and were monitored in years following tagging, and 6 were recaptured and measured. Collectively, individual tagged sharks were monitored in PKD Bay for periods of 1 to $124 \mathrm{~d}$ 
$(61 \pm 29 \mathrm{~d})$ and detected 19 to $35119(10316 \pm 6827)$ times during a single monitoring period. A total of 876872 detections were logged over all monitoring periods. No acoustically tagged sharks died immediately following capture and handling; 3 individuals were confirmed dead in weeks following tagging based on constant detection at a single receiver (i.e. no movement).

\section{Seasonal residency}

Juvenile sand tigers were monitored continuously in PKD Bay for extended periods during each season and did not routinely move in and out of the embayment (Tables $2 \& \mathrm{~S} 1$ ). As a result, the total monitoring period was equivalent to MRT or TRT for all tracked individuals. A summary of the number, size, sex, and duration of monitoring of all sharks tracked in each year is presented in Table 2.

Seasonal monitoring of acoustically tagged individuals indicated that juvenile sand tigers migrated into PKD Bay during early June to mid-July and remained in the embayment for variable amounts of time. Of the 8 sharks that returned to PKD Bay in years following tagging, the earliest date that a shark returned was June 2, which occurred in 2011. TRT for these 8 sharks ranged from 42 to $124 \mathrm{~d}$ ( $80 \pm$ $29 \mathrm{~d}$ ); one additional shark was detected in the array for a brief period $(<24 \mathrm{~h})$ in both September 2010 and 2011 but was not included in any residency analyses. MRT calculated for the 69 sharks that survived to emigrate from PKD Bay following tagging ranged from 6 to $102 \mathrm{~d}(63 \pm 25 \mathrm{~d})$. Based on regression analyses, there was a significant negative relationship between FL and residence time $(\mathrm{FL}=$ $-0.53, \mathrm{df}=58, t=-2.52, \mathrm{p}=0.01$ ), but no relationship was evident between residence time and sex $(\mathrm{df}=1, t=0.02, \mathrm{p}=0.99)$ or year $(\mathrm{df}=2, t=0.88, \mathrm{p}=$ $0.39)$.
Sharks moved out of PKD Bay predominantly in September and early October, but a small number of individuals moved out as early as July, depending on the year. In 2008, sharks exited the array from September 20 to October 4. In 2009, sharks exited from September 4 to October 4, with 17 (65\%) leaving during September and $9(35 \%)$ leaving during the first week in October. During 2010, sharks left the bay from August 13 to October 6, with $3(9 \%)$ leaving in August, $16(50 \%)$ leaving in September, and 13 $(41 \%)$ leaving in October. In 2011, sharks exited from July 20 to October 13, with $1(5 \%)$ leaving in July, 4 $(20 \%)$ leaving in August, 6 (30\%) leaving in September, and 9 (45\%) leaving in early October.

Results of GLMM analyses indicated that both average weekly day length (DL) and water temperature $(\mathrm{T})$ were significantly related to the presence (i.e. emigration) of juvenile sand tigers in 2009 ( $\mathrm{n}=$ 26; $\mathrm{DL}=38.32, z=3.58, \mathrm{p}<0.001 ; \mathrm{T}=15.12, z=3.84$ ， $\mathrm{p}<0.001), 2010(\mathrm{n}=31 ; \mathrm{DL}=18.54, z=6.56$, $\mathrm{p}<0.001 ; \mathrm{T}=1.30, z=8.91, \mathrm{p}<0.001)$, and $2011(\mathrm{n}=$ 18; $\mathrm{DL}=16.53, z=5.50, \mathrm{p}<0.001 ; \mathrm{T}=1.78, z=7.37$, $\mathrm{p}<0.001)$. Examination of inflection points $(50 \%$ probability of presence) suggested that the majority of sharks emigrated out of PKD Bay when average weekly day lengths reached 11.9, 12.1, and $12.1 \mathrm{~h}$ and average weekly water temperatures reached 16.2, 16.9, and $17.4^{\circ} \mathrm{C}$ in 2009, 2010, and 2011, respectively (Fig. 2).

\section{Space use}

Juvenile sand tigers were detected on all receivers deployed during each monitoring period, although various metrics indicated that sharks predominantly occurred in 2 separate habitats in PKD Bay. The total number of detections per receiver days for each zone varied slightly between each monitoring period, with both Zones 1 and 2 having markedly higher values

Table 2. Summary of data from acoustically tagged sharks monitored in each year of the study. Size (range; mean \pm SD) and sex $(\mathrm{M}=$ male, $\mathrm{F}=$ female) information are presented for all monitored sharks, including sharks that returned to PKD Bay in years following tagging (Returns). The extent of the monitoring period (Dates) and the number of days individual sharks were monitored during that period (Days; range; mean $\pm \mathrm{SD}$ ) are presented. FL: fork length

\begin{tabular}{|c|c|c|c|c|c|c|}
\hline \multirow{2}{*}{ Year } & \multicolumn{2}{|c|}{ Number of sharks } & \multicolumn{2}{|c|}{ Shark information } & \multicolumn{2}{|c|}{ Monitoring period } \\
\hline & Monitored & Returns & $\mathrm{M} / \mathrm{F}$ ratio & Size $\left(\mathrm{FL}_{;} \mathrm{cm}\right)$ & Dates & Days \\
\hline 2008 & 3 & NA & $0 / 3(0)$ & $89.5-92.0(91.0 \pm 1)$ & Sep 4-Oct 4 & $10-17(14 \pm 3)$ \\
\hline 2009 & 27 & 0 & $15 / 12(1.3)$ & $78.0-106.0(91.0 \pm 7)$ & Jun 30-Oct 4 & $6-88(58 \pm 28)$ \\
\hline 2010 & 34 & 4 & $20 / 14(1.4)$ & $79.0-108.0(90.0 \pm 8)$ & Jun 6-Oct 6 & $1-98(65 \pm 25)$ \\
\hline 2011 & 21 & $8^{\mathrm{a}}$ & $14 / 7(1.6)$ & $82.0-118.5(98.0 \pm 11)$ & Jun 2-Oct 13 & $1-124(66 \pm 35)$ \\
\hline
\end{tabular}



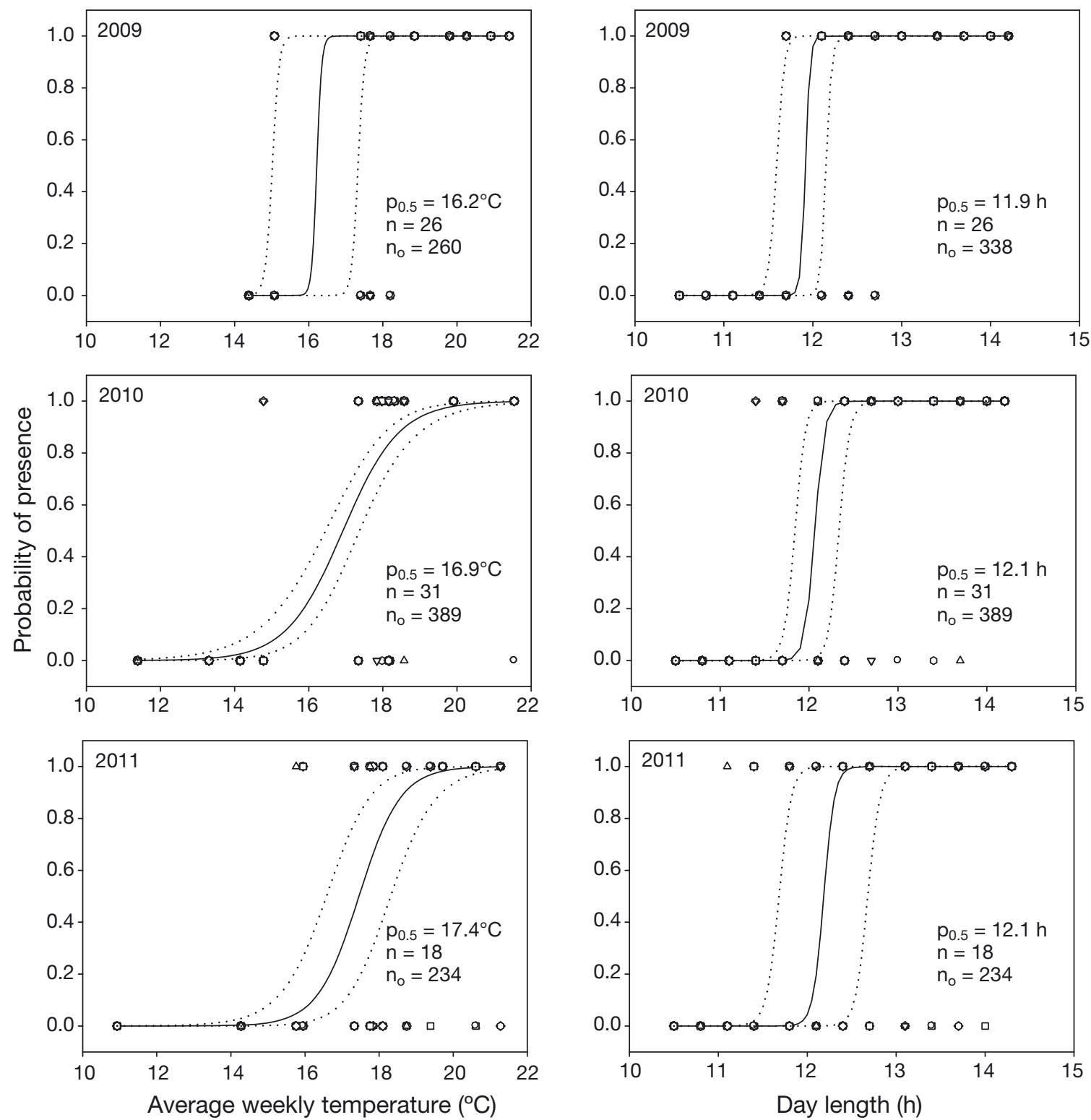

Fig. 2. Results of binomial generalized linear mixed models investigating the effects of average weekly temperature (left-hand panels) and day length (right-hand panels) on emigration of sand tigers from PKD Bay. All regressions demonstrated a significant relationship ( $\mathrm{p} \leq \mathrm{0.001}$ ), with day length being the more consistent migratory cue between years. Weekly presenceabsence data (overlapping polygons), 95\% confidence intervals (dotted lines), predicted values of $50 \%$ presence $\left(\mathrm{p}_{0.5}\right)$, number of sharks $(\mathrm{n})$, and number of observations $\left(\mathrm{n}_{\mathrm{o}}\right)$ are displayed

than either Zones 3 or 4 (Table 1). The receivers with the greatest number of detections per day varied slightly between years, although Receivers Z1-2, Z1-3, Z2-2, Z2-3, and Z2-4 consistently amassed the greatest number of detections per day in each year of deployment (Table 1). Data accrued in 2008 were not presented because of the low number of sharks tracked $(\mathrm{n}=3)$ and the abbreviated tracking period (8 to $15 \mathrm{~d}$ ).

Lattice-based activity space analyses indicated that sharks used various habitats within PKD Bay, with 2 regions emerging as areas of high use in each monitoring period (Fig. 3). Sharks consistently used one core habitat in the northern region of PKD Bay near a large wooden bridge and tidal salt marsh and a second core habitat in the western region of the bay in a channel that terminates at the mouth of the Jones River. Total seasonal activity space was similar between years (Table 3). There was no significant effect of sex or FL on 50 or $95 \%$ total activity space estimates in any year except 2011 (Table 3). 

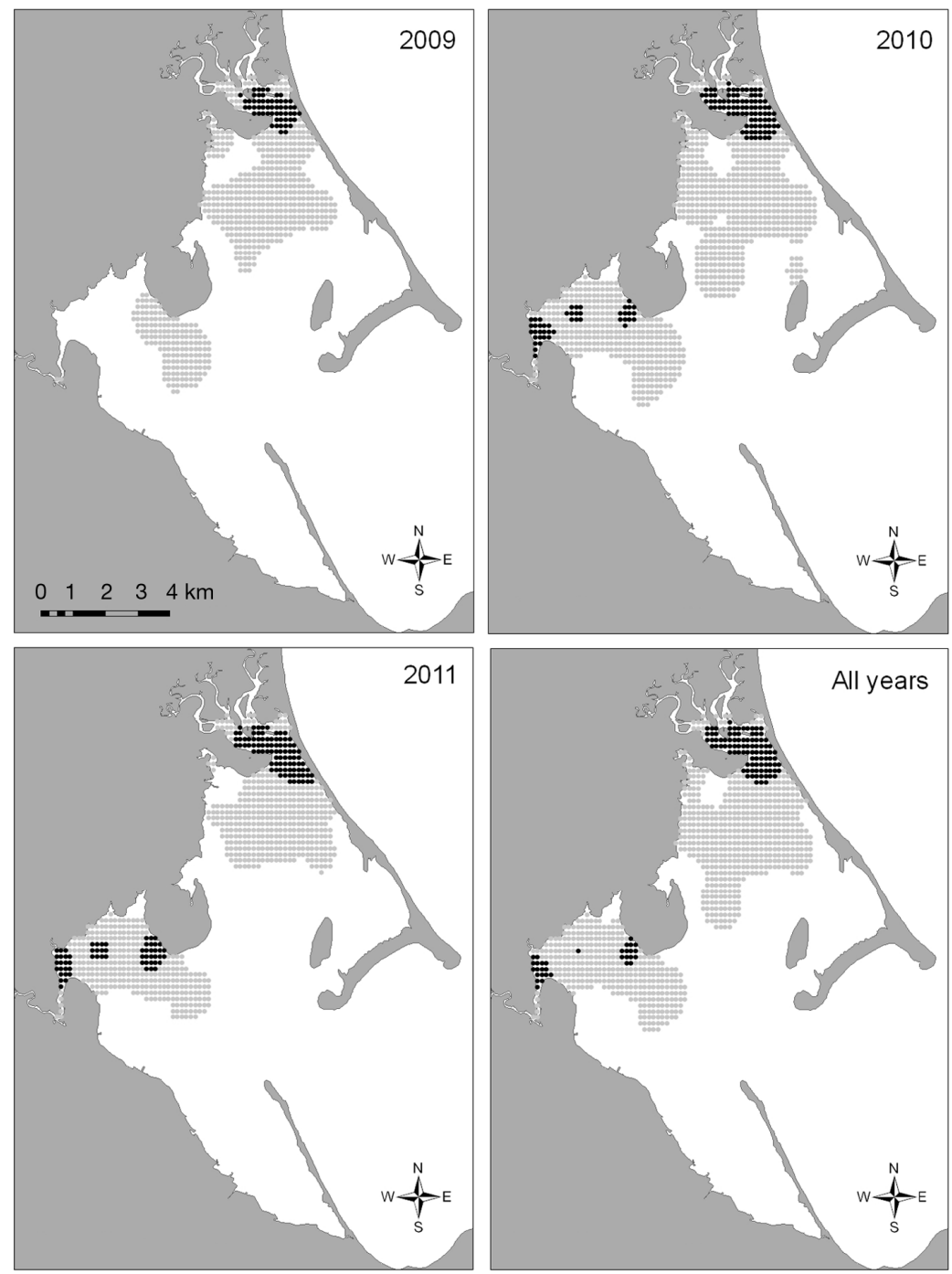

Fig. 3. Estimates of total 50\% (black dots) and 95\% (light grey dots) activity spaces of all tagged sand tigers monitored in each yearly monitoring period and cumulatively across all years

Weekly activity space varied considerably throughout each monitoring period (Table 3). Individual mean weekly $50 \%$ activity spaces were slightly different between years, varying from 0.38 to $0.72 \mathrm{~km}^{2}$ for most of the 2009 monitoring period and from 0.47 to $1.22 \mathrm{~km}^{2}$ for most of 2010 and 2011 (Fig. 4). Mean weekly 95\% activity space varied between 1.89 and $6.16 \mathrm{~km}^{2}$ for the majority of each yearly monitoring period (Fig. 4). A general increase in weekly activity space was evident during the latter stages of each monitoring period in each year, with activity space nearly doubling between the weeks spanning August 24 to September 6 in 2009 and August 17 to 30 in 2010 (Fig. 4). A smaller expansion of activity space was also evident during early October 2011, although only a single shark was tracked during the final week (October 12 to 18 ; Fig. 4). The results of GAMM analyses indicated that both 50 and $95 \%$ weekly activity space estimates were significantly related to week in nearly all years; no significant effect of week was evident in $50 \%$ activity space for 2011 (Table 3). There were no effects of sex or FL on weekly 50 and $95 \%$ activity space estimates in all years except for 2011, during which larger sharks had larger 95\% weekly activity spaces (Table 3). Average weekly temperature was significantly related to 50 and $95 \%$ weekly activity space estimates in all years of the study (Table 3); examination of resulting GAMM smoothers indicated that activity spaces were larger at lower temperatures.

Juvenile sand tigers displayed a high degree of site fidelity to core habitats of PKD Bay during each year of the study. Non-metric multidimensional scaling plots generated using all SFI data from each year $(\mathrm{n}=74$; including 66 sharks monitored for $1 \mathrm{yr}, 6$ monitored for $2 \mathrm{yr}$, and 2 monitored for $3 \mathrm{yr}$ ) revealed distinct patterns of site fidelity within PKD Bay, with groups of sharks displaying strong site fidelity to Zones 1 and 2 and others showing varying degrees of fidelity to multiple zones (e.g. ST0924-10 represents a shark that showed near equal fidelity to both Zones 1 and 2; Fig. 5). Areas of strong site fidelity were consistent with locations of 50 and $95 \%$ activity space for all sharks (Fig. 6). SFI values ranged from 0.51 to 0.97 (0.79 \pm 0.11 ) for the 49 sharks ( $66 \%$ ) that displayed strong site fidelity to Zone 1 and 0.51 to $0.99(0.82 \pm 0.09)$ for the 21 sharks $(28 \%)$ that displayed strong site fidelity to Zone 2. However, the total number of sharks that displayed fidelity to Zone 1 was greater because of the unequal distribution of tags between Zone 1 ( $\mathrm{n}=$ $20)$ and Zone $2(n=3)$ in 2009. Four sharks $(6 \%)$ displayed moderate to strong fidelity to both Zones 1 and 2, with SFI values of 0.36 to $0.48(0.41 \pm 0.06)$ and 0.42 to $0.46(0.44 \pm 0.02)$ for Zones 1 and 2, respectively. SFI values were lower for Zone 3 ( 0.01 to 0.37 ; $0.12 \pm 0.08$ ) and Zone 4 ( 0 to $0.27 ; 0.02 \pm 0.03$ ), indicating that sharks did not use these areas as regularly as either Zone 1 or 2 . 
Table 3. Summary of results from generalized linear models (GLMs) investigating the relationship between size (fork length, FL) and sex and 50 and $95 \%$ total activity space (TAS) and generalized additive mixed models (GAMMs) examining the relationship between FL, sex, average weekly water temperature, and week on 50 and $95 \%$ weekly activity space (WAS). Sample size, range, and mean \pm SD of all activity space estimates are presented for each yearly monitoring period (2008 omitted).

Significant relationships (GLMs: $\mathrm{p}<0.05$; GAMMs: $\mathrm{p}<0.001$ ) are indicated in bold. (-) relationship not examined

\begin{tabular}{|c|c|c|c|c|c|c|c|c|c|c|}
\hline & \multirow[t]{3}{*}{$\mathrm{n}$} & \multirow{3}{*}{ Activity space $\left(\mathrm{km}^{2}\right)$} & \multirow{2}{*}{\multicolumn{2}{|c|}{ Size (FL) }} & \multirow{2}{*}{\multicolumn{2}{|c|}{ Sex }} & \multirow{2}{*}{\multicolumn{2}{|c|}{1 results- }} & \multirow{2}{*}{\multicolumn{2}{|c|}{ Week }} \\
\hline & & & & & & & & & & \\
\hline & & & $t$ & $\mathrm{p}$ & $t$ & $\mathrm{p}$ & $F$ & $\mathrm{p}$ & $F$ & $\mathrm{p}$ \\
\hline \multicolumn{11}{|l|}{2009} \\
\hline $50 \%$ TAS & 27 & $0.40-2.30(0.91 \pm 0.50)$ & 0.68 & 0.51 & 0.25 & 0.81 & - & - & - & - \\
\hline $95 \%$ TAS & 27 & $2.40-17.51(7.34 \pm 2.97)$ & 0.08 & 0.94 & 0.68 & 0.50 & - & - & - & - \\
\hline $50 \%$ WAS & 233 & $0.50-2.93(0.85 \pm 0.57)$ & -0.10 & 0.92 & 0.34 & 0.74 & 23.06 & $<0.001$ & 25.71 & $<0.001$ \\
\hline $95 \%$ WAS & 233 & $0.90-13.98(4.31 \pm 2.93)$ & 0.41 & 0.69 & 0.13 & 0.90 & 25.40 & $<0.001$ & 25.10 & $<0.001$ \\
\hline \multicolumn{11}{|l|}{2010} \\
\hline $50 \%$ TAS & 33 & $0.59-2.22(1.22 \pm 0.43)$ & 1.60 & 0.12 & -0.96 & 0.90 & - & - & - & - \\
\hline $95 \%$ TAS & 33 & $5.78-13.90(9.26 \pm 2.38)$ & 1.25 & 0.22 & 0.42 & 0.68 & - & - & - & - \\
\hline $50 \%$ WAS & 331 & $0.24-4.75(1.04 \pm 0.64)$ & 0.83 & 0.41 & 0.68 & 0.49 & 22.89 & $<0.001$ & 22.10 & $<0.001$ \\
\hline $95 \%$ WAS & 331 & $1.10-20.66(5.58 \pm 3.48)$ & 1.72 & 0.09 & 1.10 & 0.27 & 31.35 & $<0.001$ & 36.58 & $<0.001$ \\
\hline \multicolumn{11}{|l|}{2011} \\
\hline $50 \%$ TAS & 20 & $0.57-2.80(1.18 \pm 0.49)$ & 1.47 & 0.16 & 0.89 & 0.39 & - & - & - & - \\
\hline $95 \%$ TAS & 20 & $3.52-11.64(7.02 \pm 2.93)$ & 2.83 & 0.01 & 0.26 & 0.80 & - & - & - & - \\
\hline $50 \%$ WAS & 211 & $0.33-3.31(0.93 \pm 0.43)$ & 1.67 & 0.10 & 0.79 & 0.43 & 4.92 & $<0.001$ & 2.78 & $0.04^{\mathrm{a}}$ \\
\hline $95 \%$ WAS & 211 & $1.10-18.41(4.53 \pm 2.42)$ & 3.76 & $<0.001$ & 0.15 & 0.88 & 8.08 & $<0.001$ & 4.77 & $<0.001$ \\
\hline
\end{tabular}

\section{DISCUSSION}

Recently, Heupel et al. (2007) proposed that 3 criteria must be met for an area to be designated a shark nursery: (1) sharks are more commonly encountered in that area than other areas; (2) sharks have a tendency to remain or return for extended periods; and (3) the area or habitat is repeatedly used across years. Examination of data accrued during the monitoring of the juvenile sand tiger population within PKD Bay from 2008 to 2011 suggests that this region meets these 3 criteria and is worthy of classification as a nursery area. Extrapolation of observed sand tiger sizes to length-at-age data presented by Goldman et al. (2006) suggests that approximately $71 \%$ $(n=84)$ of all individuals captured within the embayment over the course of the study were young of the year (YOY; 79 to $96 \mathrm{~cm} \mathrm{FL),} 24 \%$ were Age 1 (97 to $109 \mathrm{~cm} ; \mathrm{n}=29)$, and $5 \%$ were Age $2(110$ to $130 \mathrm{~cm}$; $\mathrm{n}=6$ ). Collectively, these data suggest that PKD Bay is of particular importance as a seasonal nursery area for YOY sharks but also plays an important role for juveniles up to Age 2. Throughout the study, juvenile sand tigers used habitat within PKD Bay consistently for extended periods of time (up to $124 \mathrm{~d}$ from early June to early October) in successive years and exhib- ited strong site fidelity to specific habitat during their seasonal residency. In addition, the return of at least 10 sharks to the embayment in successive years (8 sharks with acoustic tags and 2 with NMFS conventional tags), 2 of which revisited the embayment for extended periods in 3 consecutive years, supports the importance of PKD Bay as a seasonal juvenile sand tiger nursery area during the first few years of life. Lastly, although empirical estimates of abundance are unavailable for the surrounding region, the historical rarity of sand tigers in northern New England (i.e. north of Cape Cod; Bigelow \& Schroeder 1953), coupled with the high abundance of individuals in PKD Bay and the lower frequency of encounters in surrounding regions (Skomal 2007; authors' pers. obs.), suggests that this species is more commonly encountered in this embayment than in surrounding coastal Massachusetts waters.

Common convention suggests that shark nurseries enhance the survival of juveniles by offering abundant food resources and/or protection from larger predators (Branstetter 1990, Castro 1993, Simpfendorfer \& Milward 1993, Heithaus 2007, Heupel et al. 2007). Furthermore, individuals (or groups of individuals) have been shown to use specific habitats within a nursery area in response to spatial and temporal 

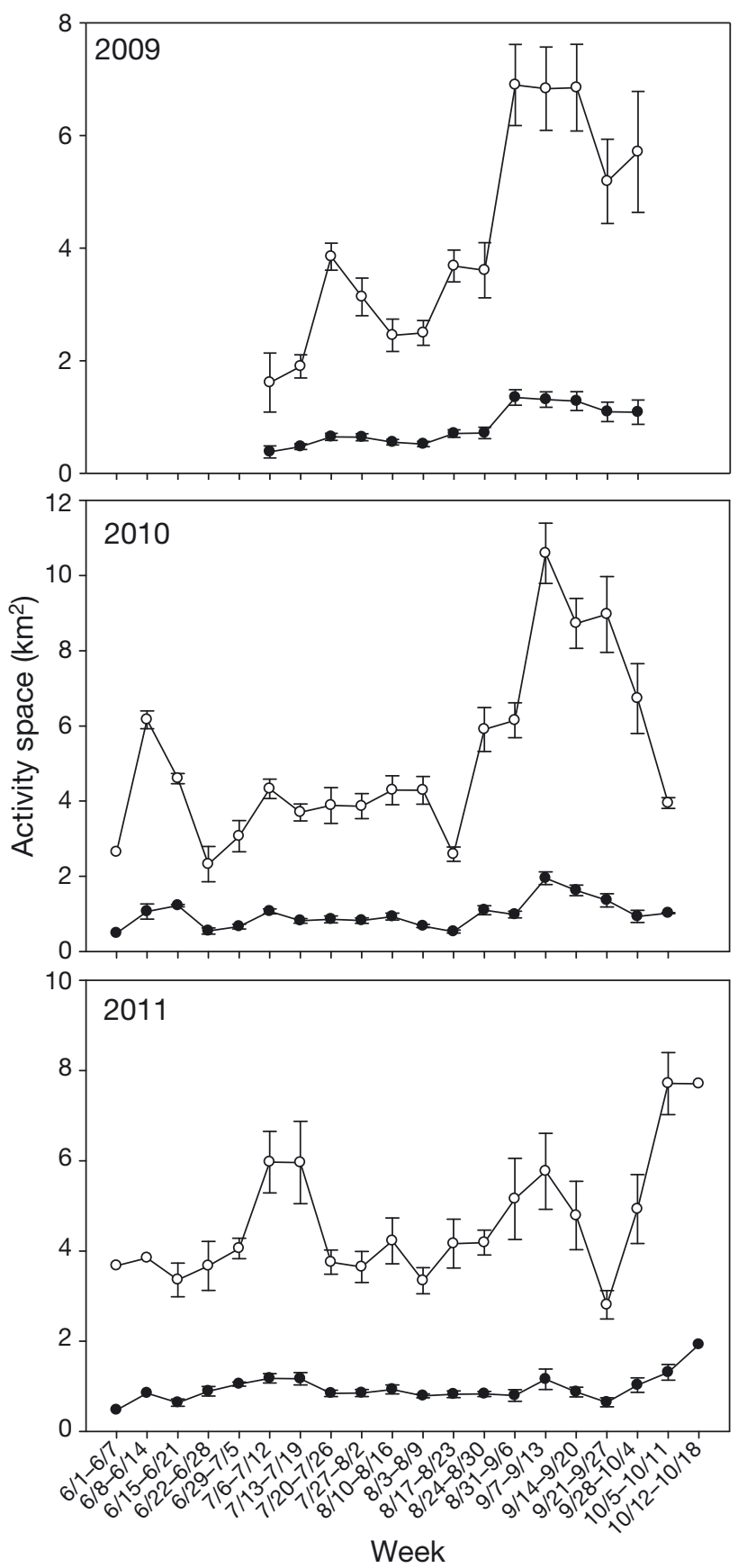

Fig. 4. Mean weekly $50 \%$ (•) and $95 \%$ (०) activity space estimates for the $20 \mathrm{wk}$ period of June 1 to October 18 of each monitoring period. Error bars represent SD of each weekly average

variations in a number of factors (e.g. temperature, prey abundance) that are beneficial to its occupants (Heithaus 2007, Heupel et al. 2007). For sand tigers in PKD Bay, such factors must be substantially beneficial given the energetic costs of migration from southern grounds. For example, acoustic transmitter detection data from receivers deployed along the east coast of the United States indicated that several acoustically tagged individuals exhibited extensive seasonal migrations, moving from PKD Bay to as far south as central Florida before returning in the following summer (J. Kneebone unpubl. data). Although empirical examination of these factors is necessary to determine the true ecological role of PKD Bay as a nursery, preliminary observations suggest that sand tigers may migrate to this region to seek refuge from predators and exploit prey resources. Throughout the study, no large predators (i.e. larger sharks) were observed in PKD Bay, and potential prey items (e.g. menhaden, shad, bluefish, crabs, etc.) were observed in relative abundance (J. Kneebone unpubl. obs.). However, within PKD Bay, given the relatively large size of the resident individuals $(\sim 80$ to $120 \mathrm{~cm})$ and the general lack of predators throughout the embayment, juvenile sand tigers more likely select habitat therein to exploit prey resources. Regardless, further research into the factors that influence the seasonal use of PKD Bay by juvenile sand tigers is warranted.

The feeding ecology of juvenile sand tigers in PKD Bay was not quantified in this study, but anecdotal evidence indicates that the sharks may seasonally inhabit the bay to exploit large aggregations of menhaden. Menhaden were observed in high abundance within PKD Bay throughout each year of the study, almost exclusively in the 2 core areas of sand tiger habitat use (Zones 1 and 2; J. Kneebone \& J. Chisholm pers. obs.). In fact, small-scale commercial fisheries for menhaden were observed in these areas of PKD Bay in each year of the study, with fishermen traveling from distant locations to exploit the abundance of menhaden. Sand tigers are known predators of menhaden (e.g. Clark \& von Schmidt 1965, Compagno 2001, Gelsleichter et al. 1999), particularly north of Cape Cod (Bigelow \& Schroeder 1953), and indeed sand tigers were observed actively preying on menhaden on several occasions over the course of the study. Furthermore, and of note, the only published review of the marine resources of PKD Bay by Iwanowicz et al. (1974) reported no evidence of either menhaden or sand tigers within the embayment, suggesting that the recent emergence of both species may be related. Unfortunately, no metrics were available to quantify the true distribution and abundance of menhaden in PKD Bay during the study periods or over the last $30 \mathrm{yr}$, inhibiting our ability to directly link the distribution of sand tiger sharks to menhaden abundance.

The return of 8 acoustically tagged individuals in years following tagging permitted the documenta- 


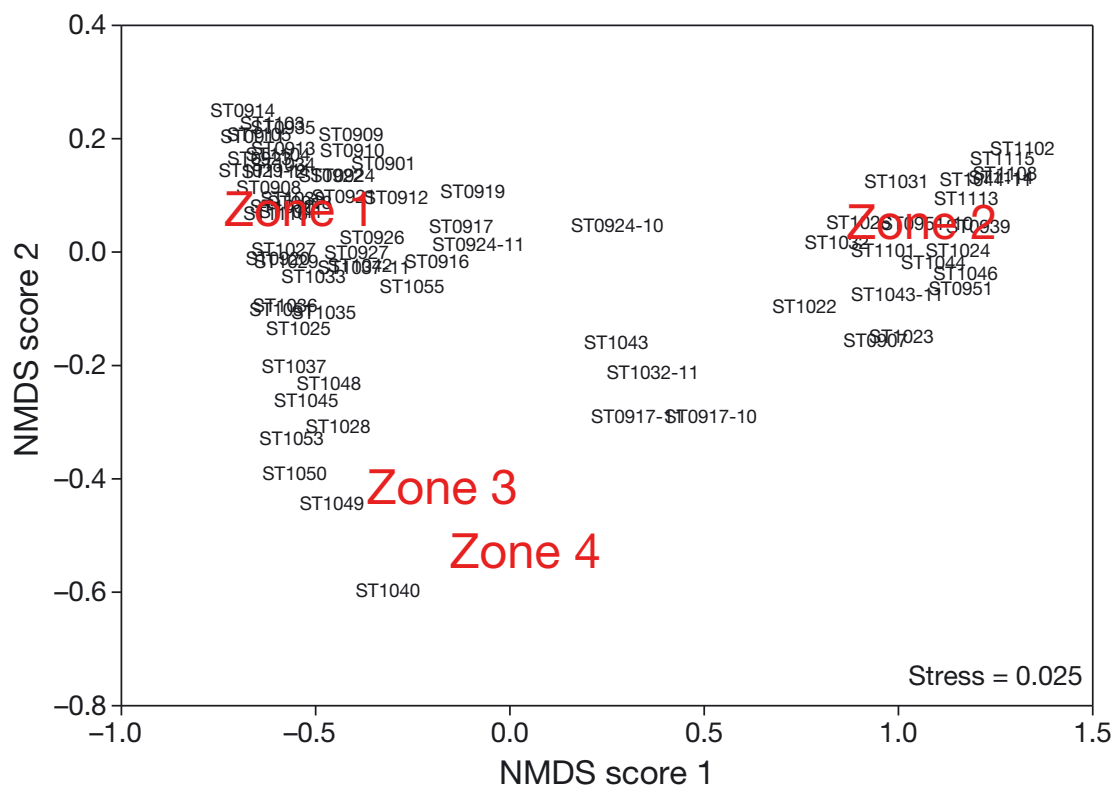

Fig. 5. Non-metric multidimensional scaling (NMDS) plot generated using site fidelity index (SFI) data from all sharks $(\mathrm{n}=74)$ monitored greater than $10 \mathrm{~d}$ during the study. Distinct clusters are visible, comprising groups of sharks that displayed strong site fidelity to Zones 1 and 2. Dispersal of points around these clusters is indicative of sharks that displayed weaker site fidelity to another zone (i.e. $\mathrm{SFI} \approx 0.1$ to 0.2 )

tion of true seasonal residency of juvenile sand tigers in PKD Bay. Returning sharks first entered PKD Bay on June 11 and June 2 in 2010 and 2011, respectively, and remained residents for varying periods in each year. In addition, a ninth shark was detected briefly $(<24 \mathrm{~h})$ near the mouth of the bay (Zone 3$)$ in midSeptember of both 2010 and 2011, presumably during its southward migration. Interestingly, this shark spent at least $43 \mathrm{~d}$ in PKD Bay in 2009 (94 $\mathrm{cm}$ at tagging), indicating that additional sand tiger nursery habitat may exist elsewhere in New England. Of note, however, all sharks from which TRT was available were at least 1 yr old; thus, TRT of YOY sharks could not be determined. Regardless, YOY sharks were among the first captured (late June to early July) and the last to exit the embayment in each monitoring season, suggesting that their residence times were comparable and potentially longer than those of older individuals.

Although the low number of returning sharks over multiple years precluded a statistical analysis of TRT, the combination of these data with estimates of MRT provided insights into the effects of sex, shark length (age), and year on seasonal residency of sand tigers in PKD Bay. The negative relationship between residence time and FL is consistent with other studies on shark nurseries (e.g. Conrath \& Musick 2010, Papastamatiou et al. 2010) and suggests that smaller (presumably younger) sharks benefit from extended habitation of the nursery area. Indeed, the 2 individuals that returned to PKD Bay for extended periods in 3 successive years exhibited $38 \%$ (81 to $50 \mathrm{~d}$ ) and $55 \%$ (94 to $42 \mathrm{~d}$ ) reductions in TRT from Age 1 to 2 .
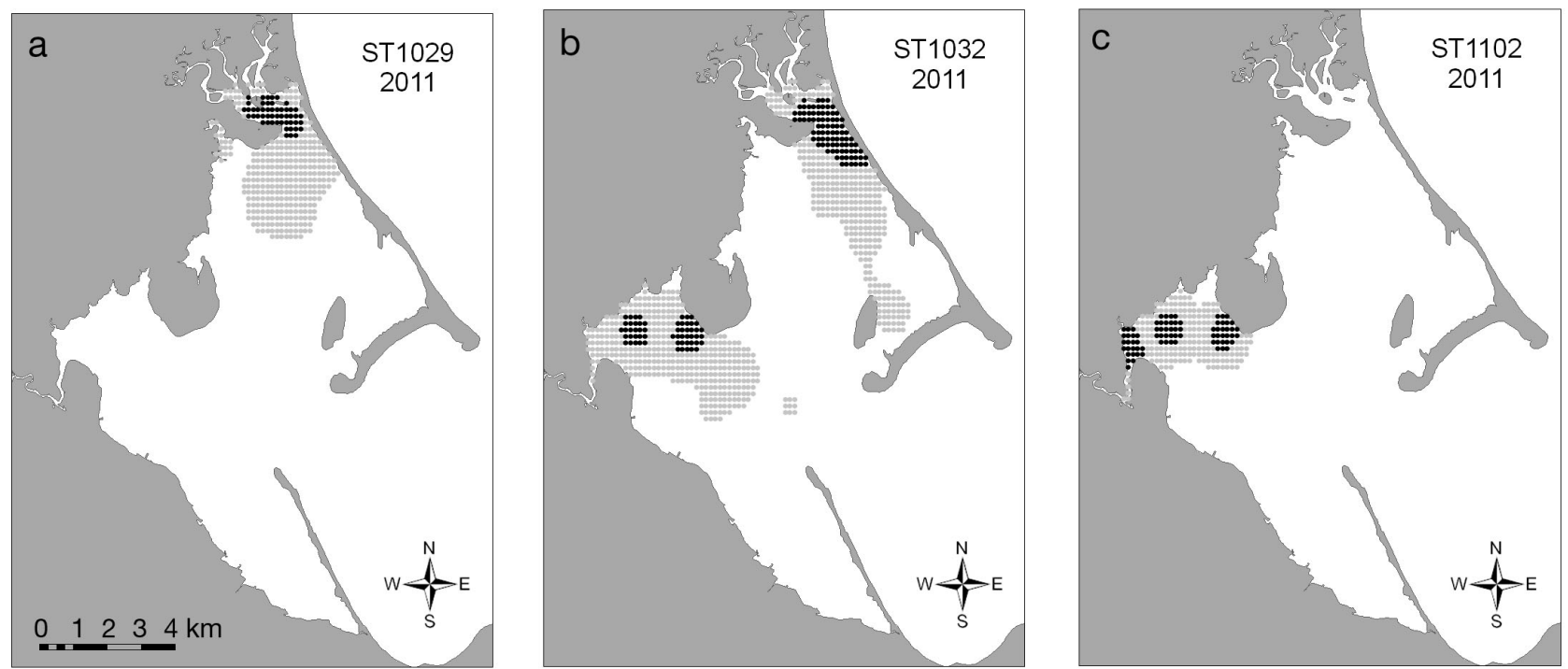

Fig. 6. Example of 3 sharks that displayed strong site fidelity to (a) Zone 1, (b) Zones 1 and 2, and (c) Zone 2 during a single monitoring period. The vast majority of sharks monitored throughout the course of the study exhibited one of these behaviors. 
In the present study, both absolute temperature (16.2 to $17.4^{\circ} \mathrm{C}$ ) and day length (11.9 to $\left.12.1 \mathrm{~h}\right)$ were significantly related to the emigration of juvenile sand tigers out of PKD Bay. Examination of the residual deviance values of each GLMM (which were lower for DL analyses in all years), the steepness of resulting DL curves (which was evidence of a stronger relationship between DL and shark presence), and the consistency of DL inflection points between years suggested that although both cues may be influential, photoperiod may be the stronger, more consistent cue. For example, with the exception of a single shark that left on October 13 in 2011, all acoustically tagged sand tigers had emigrated out of PKD Bay by nearly the same date in all years (October 4 to 6). Average water temperature during these dates was also variable between years (2009: $15.1^{\circ} \mathrm{C}$; $2010: 18.2^{\circ} \mathrm{C}$; $2011: 17.3^{\circ} \mathrm{C}$ ), further supporting the stronger influence of photoperiod on emigration. These findings are consistent with previous studies that have documented strong relationships between seasonal decreases in water temperature below threshold levels (e.g. Castro 1993, Hopkins \& Cech 2003, Carlisle \& Starr 2009) and photoperiod (e.g. Grubbs et al. 2007) and the emigration of sharks out of nursery areas. Lastly, although Heupel (2007) suggested that relative changes (as opposed to absolute changes) in water temperature provided the primary cue for the emigration of juvenile blacktip sharks Carcharhinus limbatus from summer nurseries, relative changes in water temperature were not considered influential to the migration of sand tigers out of PKD Bay because of the large temperature gradients observed within the study area. For example, data from acoustic tags that included temperature sensors (i.e. V16T tags) revealed that broad temperature fluctuations, typically of 5 to $8^{\circ} \mathrm{C}$ (e.g. 10.9 to $17.9^{\circ} \mathrm{C}$ ), were commonly encountered by individual sharks during the $6 \mathrm{~h}$ period between high and low tide, and even greater 5 to $12^{\circ} \mathrm{C}$ (e.g. 10.8 to $22.6^{\circ} \mathrm{C}$ ) differences were regularly encountered over a $24 \mathrm{~h}$ period (J. Kneebone unpubl. data).

Activity space and site fidelity analyses showed 2 primary areas of core usage in PKD Bay throughout the study period. In each year, core habitats were present in the northernmost (Zone 1) portion of the bay close to a large wooden bridge that spans the entrance to a salt marsh and in the westernmost (Zone 2) portion of the bay within a channel that terminates at the mouth of the Jones River. Within Zone 1, the bottom substrate is largely mud; however, a considerable area is occupied by shellfish aquaculture land grants, all of which use platforms suspended off the substrate to grow out juvenile oys- ters Crassostrea virginica. Sand tigers have long been known to associate with bottom structure (Bigelow \& Schroeder 1953, Bass et al. 1975, Compagno 2001); thus, the bottom structure (i.e. bridge and oyster platforms) in this area of Zone 1 may concentrate sand tiger activity. Interestingly, core habitat in Zone 2 did not possess similar structure; rather, sharks were generally encountered in a relatively deep channel present within this zone. Overall, tagged sharks consistently displayed high site fidelity to each of these areas during all seasonal monitoring periods, with groups of individuals spending their entire residency within a respective zone and others exhibiting movement between them. Not unexpectedly, the vast majority of sharks captured throughout the study were captured in these 2 areas.

Examination of water quality data gathered biweekly at 8 stations within PKD Bay by the Provincetown Center for Coastal Studies Cape Cod Bay Monitoring Program ${ }^{2}$ and high-resolution temperature data collected by this study indicated that, on average, core areas in Zones 1 and 2 experienced the highest chl $a$, temperature, and turbidity and lowest dissolved oxygen and salinity levels compared to any other monitored area in each year of the study. Previous telemetry studies on coastal shark populations have suggested that dissolved oxygen (e.g. Carlson \& Parsons 2001, Heithaus et al. 2009), salinity (e.g. Heupel \& Simpfendorfer 2008, Ubeda et al. 2009), temperature (e.g. Carlisle \& Starr 2009, Espinoza et al. 2011), and prey abundance (e.g. Heupel \& Hueter 2002, Torres et al. 2006) influence habitat use and likely affect juvenile sand tiger habitat choice in PKD Bay to some degree. For example, available water quality data suggest that both core habitats exhibited relatively high primary productivity throughout the course of the study, a scenario that may increase prey abundance in these areas. Furthermore, adult menhaden are known to exist in highly productive waters (Bigelow \& Schroeder 1953), and the high relative abundance of these forage fish observed in both core habitats may act to concentrate sand tiger activity. Further research is necessary to adequately assess the influence of environmental factors on sand tiger habitat use in these dynamic areas.

During each seasonal monitoring period, sand tiger sharks were detected least often in the southernmost area of the bay (Zone 4), suggesting limited or no preference for this habitat. Given the need to distribute tagging effort throughout the bay to adequately

\footnotetext{
2Provincetown Center for Coastal Studies, 115 Bradford Street, Provincetown, MA 02657, USA; www.coastalstudies.org
} 
assess the behavior of the sharks therein, repeated efforts were made to sample sharks in Zone 4, but no sharks were captured in any year. In fact, site fidelity indices indicated that only 1 shark (ST1040) spent considerable time in Zone $4(\mathrm{SFI}=0.27)$, with all remaining sharks spending little or no time (SFI $=0$ to 0.07 ) in this area. In addition, the limited number of detections observed within Zone 4 likely was not a function of the limited number of receivers deployed in that area $(\mathrm{n}=2)$. Within Zone 4 , these receivers were deployed in the only deep channel present throughout the zone (Fig. 1), an area in which sharks likely would have been encountered if present. In addition, although sharks may have spent some time on a large tidal flat in the western portion of the zone (i.e. were undetected), the vast majority of the monitored sharks were observed to be in other regions of PKD Bay (i.e. Zones 1 to 3) for extended periods throughout their residency; there were few periods where sharks were unobserved for extended periods of time (i.e. $>24 \mathrm{~h}$ ). As a result, even if sharks did venture into Zone 4 during these unobserved periods, the overall amount of time spent in Zone 4 would have been much reduced (relative to the other zones). As a result, we are confident that the limited detections in this region are indicative of limited use and not a result of the receiver deployment.

Several factors may contribute to the consistent limited use of Zone 4 by juvenile sand tigers. Interestingly, the high-resolution temperature data collected in this study as well as dissolved oxygen and salinity data gathered at several stations by the Provincetown Center for Coastal Studies Cape Cod Bay Monitoring Program were comparable between all zones during each monitoring period. Moreover, Zone 4 also exhibited many of the same physical characteristics of core habitats in Zones 1 and 2 (e.g. relatively deep channels, eelgrass flats, river inflow). However, despite these similarities, Zone 4 differed from other zones in its proximity to Plymouth Harbor, a relatively large commercial and recreational boating port with an abundance of human activity. Previous studies have suggested that high human activity (i.e. boat traffic) may displace sharks from otherwise suitable habitat (e.g. Carrier \& Pratt 1998, Garla et al. 2006, Ward-Paige et al. 2010, Taylor et al. 2011). Consequently, the high degree of human activity in Zone 4, in comparison to Zones 1 and 2, may influence the limited use of this area by juvenile sand tigers. Although the available data shed some light on potential factors contributing to the core habitat use of juvenile sand tigers in PKD Bay, a more detailed assessment is warranted.
As observed during sampling and visualized by the nMDS ordination, 2 distinct groups of sharks were observed during each yearly monitoring period. As noted above, these groups exhibited strong site fidelity to Zones 1 and 2, with varying degrees of periodic movement into adjacent zones (i.e. Zones 3 or 4). Site fidelity to each zone was also tightly linked to an individual's capture location; all but 2 acoustically tagged sharks (97\%) exhibited strong fidelity to the zone in which they were tagged. In addition, 4 of the 8 individuals tracked in multiple years exhibited strong site fidelity to the same zone in each year. Interestingly, 26 sharks ( $35 \%$ of those included in the SFI analysis) exhibited a habitat switch at some point during their seasonal residency, moving from Zone 1 to 2 (or vice versa) and remaining there for an extended period. This was also evident in 4 sharks tracked in multiple years; these sharks either 'switched' zones (i.e. swapped fidelity from Zone 1 to 2 or vice versa) or displayed mixed fidelity to each zone during years following tagging. Similar results were presented by Papastamatiou et al. (2009), who documented that groups of blacktip reef sharks Carcharhinus melanopterus displayed strong site fidelity to 2 distinct adjacent habitats while exhibiting some degree of movement between the 2 areas. An investigation into the factors that influence the movement between core habitats was beyond the scope of this study; however, movements possibly occurred in relation to shifts in prey abundance and/or other density-dependent mechanisms.

The strong site fidelity displayed by juvenile sand tigers to Zones 1 and 2 resulted in relatively low but consistent weekly activity space estimates throughout the duration of the study. Activity space estimates were similar between sharks that displayed fidelity to Zones 1 and 2, with observed increases generally occurring because of movement between core habitats. In general, these movements occurred sporadically throughout each yearly monitoring period but became more frequent beginning in late August as sharks began to migrate out of PKD Bay. As expected, periods (weeks) during which movement between zones or out of the embayment was observed were accompanied by concomitant increases in weekly activity space. Accordingly, the significant relationship of week and weekly activity space observed in 2009 and 2010 likely was a result of increases in activity space that occurred during the period prior to emigration from PKD Bay. Although no significant relationship was observed in 2011, visible inspection of scatterplots of the data indicated that many sharks displayed increased activity spaces 
in their final weeks as residents of PKD Bay. Similar observations of increased activity space immediately prior to migration out of a region have also been reported for juvenile sandbar sharks Carcharhinus plumbeus (Rechisky \& Wetherbee 2003). For PKD Bay, such increases in activity space possibly are the result of increased foraging or, given the strong site fidelity of sharks to Zones 1 and 2, simply movement out of the embayment.

Water temperature and, to a lesser extent, FL appeared to have a significant effect on sand tiger activity space during their seasonal residency. GAMM results indicated that average weekly water temperature significantly affected sand tiger 50 and $95 \%$ activity space in each yearly monitoring period, with larger activity spaces observed at lower temperatures. Conversely, Simpfendorfer et al. (2011) reported significant positive correlations between water temperature and mean river distance (activity space) for juvenile smalltooth sawfish Pristis pectinata in a Florida estuary. A significant positive relationship was also evident between shark length (FL) and activity space in 2011, a finding consistent with previous studies (e.g. Morrissey \& Gruber 1993, Simpfendorfer et al. 2011). Interestingly, no relationship was evident between these parameters in either 2009 or 2010, likely because of the lack of large individuals (i.e. $\geq 110 \mathrm{~cm}$ ) tracked in these years.

Given the overall importance of nursery habitat to the growth and survival of young individuals, particularly from threatened populations, the identification of PKD Bay as juvenile sand tiger nursery area (i.e. $\mathrm{EFH}$ ) is of particular importance for the future management and conservation of this species. First and foremost, the results of this study will permit the designation of juvenile sand tiger EFH north of Cape Cod, a region previously devoid of sand tiger EFH in existing management documents (NMFS 2009). Furthermore, demographic analyses have suggested that sand tiger population growth rates are highly sensitive to juvenile survival (Cortés 2002, Goldman 2002); thus, the additional protection of sand tiger nursery habitat in PKD Bay, possibly as a NOAA Habitat of Particular Concern, may be warranted.

Acknowledgements. This study would not have been possible without the support of several individuals. We gratefully acknowledge D. Lindamood for enabling the initial documentation of sharks in PKD Bay; D. Beers and the Duxbury Harbormaster's Office for providing dockage; A. Danylchuk for tags, receivers, and creative input; M. Winton for creative and insightful input on data modeling; P. duBois and A. Mansfield of the Jones River Environmental Heritage Center for logistical support; D. Barry for helpful assistance with the lattice-based activity space analysis; the numerous volunteers who helped with tagging and receiver maintenance; and the 3 anonymous reviewers whose comments improved the quality of this manuscript. This research was funded by awards from the NOAA Proactive Conservation Program, the Sea World Conservation Society, and the Massachusetts Environmental Trust as well as support from the Federal Aid in Sportfish Restoration Act. This is Massachusetts Division of Marine Fisheries Contribution No. 40.

\section{LITERATURE CITED}

Aires-da-Silva AM, Gallucci VF (2007) Demographic and risk analyses applied to management and conservation of the blue shark (Prionace glauca) in the North Atlantic Ocean. Mar Freshw Res 58:570-580

ASMFC (Atlantic States Marine Fisheries Commission) (2008) Interstate Fishery Management Plan for Atlantic Coastal Sharks. ASMFC, Washington, DC

Barry R (2011) latticeDensity: density estimation and nonparametric regression on irregular regions. $\mathrm{R}$ package version 1.0.6. Available at http://cran.r-project.org/web/ packages/latticeDensity/index.html

Barry RP, McIntyre J (2011) Estimating animal densities and home range in regions with irregular boundaries and holes: a lattice-based alternative to the kernel density estimator. Ecol Model 222:1666-1672

Bass AJ, D'Aubrey JD, Kistnasamy N (1975) Sharks of the east coast of southern Africa. IV. The families Odontaspididae, Scapanorhynchidae, Isuridae, Cetorhinidae, Alopiidae, Orectolobidae and Rhiniodontidae. Invest Rep Oceanogr Res Inst S Afr 39:1-102

Bates D, Maechler M, Bolker B (2011) lme4: Linear mixedeffects models using $\mathrm{S} 4$ classes. $\mathrm{R}$ package version 0.999375-39. Available at http://CRAN.R-project.org/ package $=$ lme 4

Beerkircher L, Shivji M, Cortés E (2003) A Monte Carlo demographic analysis of the silky shark (Carcharhinus falciformis): implications of gear selectivity. Fish Bull 101:168-174

Bigelow HB, Schroeder WC (1953) Fishes of the Gulf of Maine. Fish Bull 74

Branstetter S (1990) Early life-history implications of selected carcharhinoid and lamnoid sharks of the northwest Atlantic. In: Pratt HL Jr, Gruber SH, Taniuchi T (eds) Elasmobranchs as living resources: advances in biology, ecology, systematics and the status of the fisheries. NOAA Tech Rep 90, National Marine Fisheries Service, Silver Spring, MD, p 17-28

Branstetter S, Musick JA (1994) Age and growth estimates for the sand tiger in the northwestern Atlantic Ocean. Trans Am Fish Soc 123:242-254

> Carlisle AB, Starr RM (2009) Habitat use, residency, and seasonal distribution of female leopard sharks Triakis semifasciata in Elkhorn Slough, California. Mar Ecol Prog Ser 380:213-228

Carlson JK, Parsons GR (2001) The effect of hypoxia on three sympatric shark species: physiological and behavioral response. Environ Biol Fishes 61:427-433

Carlson JK, Cortés E, Bethea DM (2003) Life history and population dynamics of the finetooth shark (Carcharhinus isodon) in the northeastern Gulf of Mexico. Fish Bull 101:281-292 
Carlson JK, McCandless C, Cortés E, Grubbs RD, Andrews KI, MacNeil MA, Musick JA (2009) An update on the status of the sand tiger shark, Carcharias taurus, in the Northwest Atlantic Ocean. NOAA Technical Memorandum NMFS-SEFSC-585

Carrier JC, Pratt HL (1998) Habitat management and closure of a nurse shark breeding and nursery ground. Fish Res 39:209-213

Castro JI (1993) The shark nursery of Bulls Bay, South Carolina, with a review of the shark nurseries of the southeastern coast of the United States. Environ Biol Fishes 38: $37-48$

Castro J, Woodley CM, Brudeck R (1999) A preliminary evaluation of the status of shark species. FAO Fisheries Technical Paper No. 380, FAO, Rome

Clark E, von Schmidt K (1965) Sharks of the central Gulf coast of Florida. Bull Mar Sci 15:13-83

Compagno LJV (2001) Sharks of the world. FAO species catalogue for fishery purposes, No. 1, Vol 2. Food and Agriculture Organization of the United Nations, Rome

Conrath CL, Musick JA (2010) Residency, space use, and movement patterns of juvenile sandbar sharks (Carcharhinus plumbeus) within Virginia summer nursery area. Mar Freshw Res 61:223-235

Cortés E (2002) Incorporating uncertainty into demographic modeling: application to shark populations and their conservation. Conserv Biol 16:1048-1062

> Espinoza M, Farrugia TJ, Lowe CG (2011) Habitat use, movements and site fidelity of the gray smoothhound shark (Mustelus californicus Gill 1863) in a newly restored southern California estuary. J Exp Mar Biol Ecol 401:63-74

> Garla RC, Chapman DD, Wetherbee BM, Shivji M (2006) Movement patterns of young Caribbean reef sharks, Carcharhinus perezi, at Fernando de Noronha Archipelago, Brazil: the potential of marine protected areas for conservation of a nursery ground. Mar Biol 149:189-199

> Gelsleichter J, Musick JA, Nichols S (1999) Food habits of the smooth dogfish, Mustelus canis, dusky shark, Carcharhinus obscurus, Atlantic sharpnose shark, Rhizoprionodon terraenovae, and the sand tiger, Carcharias taurus, from the northwest Atlantic Ocean. Environ Biol Fishes 54:205-217

Gilmore RG (1993) Reproductive biology of lamnoid sharks. Environ Biol Fishes 38:95-114

Gilmore RG, Dodrill JW, Linley PA (1983) Embryonic development of the sand tiger shark Odontaspis taurus (Rafinesque). Fish Bull 81:201-225

Goldman KH (2002) Aspects of age, growth, demographics and thermal biology of two lamniform shark species. PhD dissertation, Virginia Institute of Marine Science, VA

Goldman KJ, Branstetter S, Musick JA (2006) A re-examination of the age and growth of sand tiger sharks, Carcharias taurus, in the western North Atlantic: the importance of ageing protocols and use of multiple back-calculation techniques. Environ Biol Fishes 77 : 241-252

Grubbs RD, Musick JA, Conrath CL, Romine JG (2007) Long-term movements, migration, and temporal delineation of a summer nursery for juvenile sandbar sharks in the Chesapeake Bay region. In: McCandless CT, Kohler NE, Pratt HL Jr (eds) Shark nursery grounds of the Gulf of Mexico and east coast waters of the United States. American Fisheries Society Symposium 50. American Fisheries Society, Bethesda, MD, p 87-107
Heithaus MR (2007) Nursery areas as essential shark habitats: a theoretical perspective. In: McCandless CT, Kohler NE, Pratt HL Jr (eds) Shark nursery grounds of the Gulf of Mexico and east coast waters of the United States. American Fisheries Society Symposium 50. American Fisheries Society, Bethesda, MD, p 3-13

Heithaus MR, Delius BK, Wirsing AJ, Dunphy-Daly MM (2009) Physical factors influencing the distribution of a top predator in a subtropical oligotrophic estuary. Limnol Oceanogr 54:472-482

Heupel MR (2007) Exiting Terra Ceia Bay: examination of cues stimulating migration from a summer nursery area. In: McCandless CT, Kohler NE, Pratt HL Jr (eds) Shark nursery grounds of the Gulf of Mexico and east coast waters of the United States. American Fisheries Society Symposium 50. American Fisheries Society, Bethesda, MD, p 265-280

> Heupel MR, Hueter RE (2002) Importance of prey density in relation to the movement patterns of juvenile blacktip sharks (Carcharhinus limbatus) within a coastal nursery area. Mar Freshw Res 53:543-550

- Heupel MR, Simpfendorfer CA (2008) Movement and distribution of young bull sharks Carcharhinus leucas in a variable estuarine environment. Aquat Biol 1:277-289

> Heupel MR, Carlson JK, Simpfendorfer CA (2007) Shark nursery areas: concepts, definition, characterization and assumptions. Mar Ecol Prog Ser 337:287-297

> Hopkins TE, Cech JJ (2003) The influence of environmental variables on the distribution and abundance of three elasmobranchs in Tomales Bay, California. Environ Biol Fishes 66:279-291

Iwanowicz HR, Anderson RD, Ketschke BA (1974) A study of the marine resources of Plymouth, Kingston, and Duxbury Bay. Monograph Series No. 17. Division of Marine Fisheries, Boston, MA

Kohler NE, Turner PA (2001) Shark tagging: a review of conventional methods and studies. Environ Biol Fishes 60: 191-223

March D, Palmer M, Alós J, Grau A, Cardona F (2010) Shortterm residence, home range size and diel patterns of the painted comber Serranus scriba in a temperate marine reserve. Mar Ecol Prog Ser 400:195-206

McCandless CT, Kohler NE, Pratt HL Jr (eds) (2007) Shark nursery grounds of the Gulf of Mexico and the east coast waters of the United States. American Fisheries Society Symposium 50. American Fisheries Society, Bethesda, $\mathrm{MD}$

> Merson RR, Pratt HL (2001) Distribution, movements and growth of young sandbar sharks, Carcharhinus plumbeus, in the nursery grounds of Delaware Bay. Environ Biol Fishes 61:13-24

Morrissey JF, Gruber SH (1993) Home range of juvenile lemon sharks, Negaprion brevirostris. Copeia 1993: 425-434

Musick JA, Branstetter S, Colvocoresses JA (1993) Trends in shark abundance from 1974 to 1991 for the Chesapeake Bight region of the U.S. Mid-Atlantic Coast. NOAA Technical Report NMFS 115

Musick JA, Harbin MM, Berkeley SA, Burgess GH and others (2000) Marine, estuarine, and diadromous fish stocks at risk of extinction in North America (exclusive of Pacific salmonids). Fisheries 25:6-30

NMFS (National Marine Fisheries Service) (1999) Final fishery management plan for Atlantic tunas, swordfish, and sharks. Highly Migratory Species Management Division, 
Office of Sustainable Fisheries, NMFS, Silver Spring, MD

NMFS (National Marine Fisheries Service) (2006) Final consolidated Atlantic highly migratory species fishery management plan. Highly Migratory Species Management Division, Office of Sustainable Fisheries, NMFS, Silver Spring, MD

NMFS (National Marine Fisheries Service) (2009) Amendment 1 to the consolidated Atlantic highly migratory species fishery management plan: essential fish habitat. Final EFH map for neonate/YOY sand tiger shark (Carcharias taurus). Highly Migratory Species Management Division, Office of Sustainable Fisheries, NMFS, Silver Spring, MD

Oksanen JF, Blanchet G, Kindt R, Legendre P and others (2011) vegan: Community Ecology Package. R package version 1.17-9. Available at http://CRAN.R-project.org/ package $=$ vegan

Papastamatiou YP, Lowe CG, Caselle JE, Friedlander AM (2009) Scale-dependent effects of habitat on movements and path structure of reef sharks at a predator-dominated atoll. Ecology 90:996-1008

Papastamatiou YP, Friedlander AM, Caselle JE, Lowe CG (2010) Long-term movement patterns and trophic ecology of blacktip reef sharks (Carcharhinus melanopterus) at Palmyra Atoll. J Exp Mar Biol Ecol 386:94-102

Pincock DG (2012) False detections: What are they and how to remove them from detection data. Vemco Document \#: DOC-004691 Version 03. Vemco Division, AMIRIX Systems. Available at http://vemco.com/pdf/false_detections .pdf

R Core Development Team (2011) R: a language and environment for statistical computing. $\mathrm{R}$ Foundation for Statistical Computing, Vienna, Austria. ISBN 3-90005107-0, URL www.R-project.org

Rechisky EL, Wetherbee BM (2003) Short-term movements of juvenile and neonate sandbar sharks, Carcharhinus plumbeus, on their nursery grounds in Delaware Bay. Environ Biol Fishes 68:113-128

Simpfendorfer CA, Milward NE (1993) Utilisation of a tropical bay as a nursery area by sharks of the families Carcharhinidae and Sphyrnidae. Environ Biol Fishes 37 : 337-345

Editorial responsibility: Kenneth Sherman, Narragansett, Rhode Island, USA
Simpfendorfer CA, Heupel MR, Hueter RE (2002) Estimation of short-term centers of activity from an array of omnidirectional hydrophones, and its use in studying animal movements. Can J Fish Aquat Sci 59:23-32

Simpfendorfer CA, Yeiser BG, Wiley TR, Poulakis GR, Stevens PW (2011) Environmental influences on the spatial ecology of juvenile smalltooth sawfish (Pristis pectinata): results from acoustic monitoring. PLoS ONE 6: e16918

Skomal GB (2007) Shark nursery areas in the coastal waters of Massachusetts. In: McCandless CT, Kohler NE, Pratt HL Jr (eds) Shark nursery grounds of the Gulf of Mexico and east coast waters of the United States. American Fisheries Society Symposium 50. American Fisheries Society, Bethesda, MD, p 17-33

Springer S (1967) Social organization of shark populations. In: Gilbert PW, Mathewson RF, Rall DP (eds) Sharks, skates, and rays. Johns Hopkins Press, Baltimore, MD, p 149-174

Taylor S, Sumpton W, Ham T (2011) Fine-scale spatial and seasonal partitioning among large sharks and other elasmobranchs in southeastern Queensland, Australia. Mar Freshw Res 62:638-647

Torres LG, Heithaus MR, Delius B (2006) Influence of teleost abundance on the distribution and abundance of sharks in Florida Bay, USA. Hydrobiologia 569:449-455

Ubeda AJ, Simpfendorfer CA, Heupel MR (2009) Movements of bonnetheads, Sphyrna tiburo, as a response to salinity change in a Florida estuary. Environ Biol Fishes 84:293-303

Ward-Paige CA, Mora C, Lotze HK, Pattengill-Semmens CV, McClenachan L, Arias-Castro E, Myers RA (2010) Largescale absence of sharks on reefs in the greater Caribbean: a footprint of human pressures. PLoS ONE 5:e11968

> Watsky M, Gruber SH (1990) Induction and duration of tonic immobility in the lemon shark Negaprion brevirostris. Fish Physiol Biochem 8:207-210

Wood SN (2011) gamm4: generalized additive mixed models using mgcv and lme4. R package version 0.1-5. Available at http://CRAN.R-project.org/package=gamm4

Zuur A, Ieno EN, Walker N, Saveiliev AA, Smith GM (2009) Mixed effects models and extensions in ecology with R. Springer, New York, NY

Submitted: April 30, 2012 ; Accepted: August 7, 2012 Proofs received from author(s): November 28, 2012 